\title{
Post Auricular Fascial Flap in Otoplasty
}

\author{
AMANY E. ZEIN ELDEEN, M.Sc.*; TAREK F. KISHK, M.D.**; HANAN A. DAWOUD, M.D.** and \\ AHMED A. TAALAB, M.D.** \\ The Department of Plastic and Reconstructive Surgery, The Medical Complex Hospital for Health Insurance, Tanta* and \\ Faculty of Medicine, Menoufia University**, Egypt
}

\begin{abstract}
Objective: To compare otoplasty with post-auricular fascial flap and otoplasty without the flap as regard deformities set back and hide if suture extrusion.

Background: Prominent ear is considered as a frequent hereditary deformity affecting $5 \%$ of the population. It may cause psychological problems at any age. Modern prominent ear surgery attempts to return the ears to their normal position with soft margin outlines and attempts to perform a uniform correction without the interference of surgical evidence.

Method: This study will include 31 patients presented with congenital prominent ear deformity in The Plastic Surgery Department, Faculty of Medicine, Menoufia University in the period from February 2018 up to February 2020. All studied patients were subjected to take a full history, systemic examination, and local examination of the ear. The patients were classified into 2 groups. Group A (15 patients) underwent otoplasty with postauricular fascial flap, while group B (16 patients), otoplasty without postauricular fascial flap.

Results: There was no statistically significant difference detected between patients underwent otoplasty with or without the post-auricular fascial flap as regard duration of surgery, and complications.

Conclusion: The otoplasty with post-auricular fascial flap yields excellent patient and parent satisfaction with a natural harmonious look and minimal complication especially those related to sutures demonstrating its efficacy in preventing these complications, but with no difference with otoplasty without post-auricular fascial flap.
\end{abstract}

Key Words: Otoplasty - Post-auricular fascial flap - Prominent ear.

No Funds.

No Conflict of Interest.

\section{INTRODUCTION}

The prominent ear is a hereditary common deformity that affects approximately $5 \%$ of the population. It can lead to psychological issues at any age [1]. There is no known cause of ear deformities. It has been proposed that ear deformities are caused by missing or misplaced muscles around the ear. Some newborns have extremely soft, pliable ears, when these children have prominent ears and they lie on their sides the ears tend to fold forward against the head, tending to make them more prominent [2]. Modern prominent ear surgery attempts to return the ears to their normal position with soft margin outlines and attempts to perform a uniform correction without the interference of surgical evidence [3]. The standard of initial attempts to correct the prominent ear was tissue excision, which included post-auricular skin and strips of conchal cartilage [4].

The concho-scaphoid and concho-mastoid suturing utilized with permanent sutures as described by Mustarde with the addition of postauricular superficial muscular aponeurotic system (SMAS) flap sutured to the helical rim to cover the permanent suture [5].

These techniques depend on strong nonabsorbable sutures to medialize the auricle. The Mustarde and Furnas types of sutures gained popularity in the creation of a smooth anti-helical fold and reducing of the conchal-mastoid angle, respectively [6].

These techniques are characterized by a lower rate of complications, cartilage-sparing technique which is considered a safe and effective way to correct the prominent ear. However, using permanent sutures causes different types of complications related to their presence as sutures can erode through the skin and become exposed. Also, they cause pain secondary to the prickling dermis from beneath [6].

To bury the post-auricular sutures and decrease the complications, the post-auricular flap was used [7].

The post-auricular fascial flap acts as a refinement to the technique of cartilage-sparing in the 
prominent ear correction with lessened complications. In addition, the flap influences the recurrence rate [7].

The posterior suturing with post-auricular fascial flap otoplasty technique was developed to reduce the rising rate of post-auricular suture extrusion and recurrence with the cartilage-sparing techniques of Mustarde [8].

Aim of the work:

To compare between otoplasty with postauricular fascial flap and otoplasty without the flap as regard deformities set back and hide if suture extrusion.

\section{PATIENTS AND METHODS}

The present study was aiming to compare otoplasty with post-auricular fascial flap and otoplasty without the flap regarding deformities set back and hide if suture extrusion.

The current study was conducted on 31 patients who presented with congenital prominent ear deformity at The Plastic Surgery Department, Faculty of Medicine, Menoufia University, in the period from February 2018 up to February 2020.

The inclusive criteria include:

- Both male and female.

- Age varying from 4 years old to 13 years old with normal general condition and normal ranges of laboratory investigations.

\section{Exclusion criteria:}

- Age of patients less than 1-year-old and above 13 years old.

- Patients with tumor or trauma and poor general condition who unfit for surgery.

- Each patient was assessed by taking full history to detect any medical disease and for evaluation to be fit for the surgery.

\section{Local examination for the ear:}

The ear has a vertical length of $5-6 \mathrm{~cm}$. The ear's vertical axis is inclined $15-20^{\circ}$ distally. The width is near fifty-five percent of the vertical length. The ear's vertical height is $5-6 \mathrm{~cm}$ and therefore should roughly correspond to the length between the helical root and the orbital rim.

The ear superior-most point must be at the same level as the lateral point of the eyebrow, and the lobule inferior part must be at the level with the sub-nasale.
The auriculo-cephalic angle must be between 25-35 degrees in a range, and it is defined as the of the auricle protrusion out of the scalp.

To evaluate the protrusion of the auricle, measurements were taken at the most lateral projection in the mid-auricle $(16-18 \mathrm{~mm})$, the rim superior most aspect $(10-12 \mathrm{~mm})$, and at the inferior helical $\operatorname{rim}(20-22 \mathrm{~mm})$.

A systematic examination of the ear begins with a careful inspection of the auricle and postauricular skin. Any tenderness, obvious abnormalities, discharge, or surgical scars should be evaluated. The presence of enlarged pre- or post-auricular lymph nodes can also be noted. Evidence of either a localized or generalized skin disorder may also be present.

Pre-surgery measurements are taken at three different levels on both ears. Quantitatively assess the projection for the upper, middle, and lower thirds of the ear. These measurements are then repeated at the end of the procedure [9].

An alternative method is the use of pre- and post-surgery facial photographs to assess the measurements change, made from the mid-face to the end of the face and from the end of the face to the end of the pinna.

Laboratory investigations: Complete blood counts $(\mathrm{CBC})$ and bleeding profile such as prothrombin concentration and time.

Pre-operative and postoperatively standardized medical photography, for evaluation of all patients.

Local examination of the ear was done as previous operation, recurrence, trauma, and tumor, and then evaluation of the patient to detect any type of operation to be done which are (otoplasty with postauricular fascial flap or otoplasty without postauricular fascial flap).

\section{Timing of otoplasty:}

Waiting until patients are at least 5 years old is the choice preferred by most surgeons. The auricle is then 90-95 percent of adult size at this age. The key benefit of operating otoplasty in early childhood is that the social implications of the defect are minimized. Furthermore, the more pliable cartilage of children and the defects of the ear can be more easily corrected with cartilage-sparing surgery.

\section{Surgical techniques:}

- Group A (15 patients): Otoplasty with postauricular fascial flap. 
Induction of general anesthesia followed by infiltration of postauricular skin with lignocaine $2 \%$ and adrenaline 1:200,000. Skin incision was done in the post-auricular skin through the epidermis and dermis, short of the fascial layer underneath.

The skin was elevated off this layer until enough exposure was obtained. The fascial layer was then incised along the helical margin and carefully dissected off the underlying cartilage. Elevation of this layer was continued as far as the mastoid to obtain adequate exposure of the whole of the medial surface of the cartilage as well as the mastoid periosteum. The extent of the flap was determined by the number of sutures needed to obtain correction in a manner to ensure complete coverage of all sutures. Concho-mastoid sutures were placed first, followed by the Mustarde sutures creating the antihelical fold. Prolene 4.0 suture material was used in all sutures. The sutures were tightened, and then the facial flap was advanced back over the cartilage to cover the sutures and knots. Trimming of Excess fascial tissue was done, then the flap sutured along the helical rim using vicryl 5.0 sutures. The skin was then closed, and a head bandage was applied for one week.

- Group B (16 patients): Otoplasty without postauricular fascial flap.

For the shaping of the antihelix, a combination of Furnas sutures 7 for conchal setback and Mustarde sutures 6 is commonly used. When possible, cartilage shaving is performed to reduce the conchal bowl projection.

\section{Skin and soft tissue excision:}

A fusiform excision is made depending on the postauricular sulcus, leaving $1.5 \mathrm{~cm}$ of the free auricle. Injection of the area with $1 \%$ lidocaine with 1:100,000 epinephrine was done.

Then, make the planned incision with a 15blade and carefully excise the skin and soft tissue from the posterior cartilaginous framework.

Elliptical shave excision of cartilage with a 15 blade is performed in patients with a deep conchal bowl until the ear can be rotated to the correct position.

\section{Formation of antihelix using mustarde sutures:}

Posteriorly, undermine the skin over the free edge of the auricle for exposing the area for Mustarde suture placement.
To determine the proper position of the antihelical fold, apply pressure to the ear. Use two 30gauge needles to mark this location.

Place two to three non-absorbable horizontal mattress sutures through the posterior perichondrium, cartilage, and anterior perichondrium, avoiding the anterior skin, and ligate them to reconstruct the antihelical fold.

\section{Conchal setback:}

In the way between concha and the mastoid periosteum, put three horizontal parallel nonabsorbable sutures. They pass via the cartilage, posterior, and anterior perichondrium but not inside the skin.

All sutures are in place. The $1^{\text {st }}$ suture runs from the concha cymba to the mastoid periosteum. The $2^{\text {nd }}$ one runs from the mastoid periosteum to the concha cavum. Lastly, the superior suture is inserted into the fossa triangularis and pulls the concha medially and posteriorly.

Then, close the incisions with a running Black nylon suture 4-0, taking care not to disrupt the conchal setback sutures.

Then an assessment of outcome by measuring from the mastoid skin to the most prominent part of the helix pre and post-operatively.

\section{Statistical analysis [10]:}

The data were organized and analyzed by SPSS (statistical package for the social science software) statistical package version 20.0 on IBM.

The normal distribution was analyzed by the Kolmogorov-Smirnov test. For clarification of quantitative, range (maximum and minimum), standard deviation and mean were used. The significance of the results was evaluated at the $5 \%$ level.

\section{The following tests were carried out:}

1- Chi-square test was done for categorical variables.

2- Student $t$-test was done for normally quantitative variables.

4- Mann Whitney test was carried out on abnormally quantitative variables.

\section{RESULTS}

Patients were classified into 2 groups:

- Group (A): Including 15 patients with Otoplasty with postauricular fascial flap. 
- Group (B): Including 16 patients with Otoplasty without postauricular fascial flap.

Age in the group (A) was ranged between 4-7 years with mean \pm S.D. $5.13 \pm 0.915$ years while in the Group (B) was ranged between 4-7 years with mean \pm S.D. $5.38 \pm 1.204$ years. There were no statistically significant differences detected between groups $(p=0.572)$ (Table 1$)$.

Sex in the group (A) showed that $9(60.0 \%)$ were male and 6(40.0\%) were female, while in the group (B) 4(25.0\%) were male and $12(75.0 \%)$ were female. There were no statistically significant differences between groups where $p=0.073$ (Table 2).

Concerning the site, group (A) 7(46.7\%) were in the lower site, $3(20.0 \%)$ in the middle site, and $5(33.3 \%)$ in the upper site while in group (B) $5(31.3 \%)$ in the lower site, $4(25.0 \%)$ in the middle site, and $7(43.8 \%)$ in the upper site. There were no statistically significant differences between groups where $p=0.678$ (Table 3 ).

Protrusion in group (A) ranged between 26$38 \mathrm{~mm}$ with mean \pm S.D. $32.27 \pm 4.367 \mathrm{~mm}$ while in group (B) they ranged between $24-37 \mathrm{~mm}$ with mean \pm S.D. $30.38 \pm 4.703 \mathrm{~mm}$. There were no statistically significant differences between groups where $p=0.175$ (Table 4).

The duration of surgery in group (A) ranged between 30-60 minutes with mean \pm S.D. $43.67 \pm$ 10.431 minutes while in group (B) it ranged between 30-70 minutes with mean \pm S.D. $46.25 \pm$ 10.408 minutes. There were no statistically significant differences between groups where $p=0.892$ (Table 5).

Table (6) compares the two studied groups in terms of patient complications, revealing that there were no detected statistically significant differences between groups (Table 6).

Table (1): Comparison between two groups as regard to patient's age (years).

\begin{tabular}{lcccc}
\hline Age & $\begin{array}{c}\text { Group (A) } \\
(\mathrm{n}=15)\end{array}$ & $\begin{array}{c}\text { Group (B) } \\
(\mathrm{n}=16)\end{array}$ & $\mathrm{U}$ & $p$-value \\
\hline Min.-Max. & $4-13$ & $4-13$ & 105.50 & 0.572 \\
Mean \pm S.D & $5.13 \pm 0.915$ & $5.38 \pm 1.204$ & & \\
\hline
\end{tabular}

$\mathrm{U}$ : Mann-Whitney test.

$p$ : $p$-value for comparing between the two studied groups.

*: Statistically significant at $p<0.05$.
Table (2): Comparison between two groups as regard to patient's sex.

\begin{tabular}{|c|c|c|c|c|c|}
\hline \multirow{2}{*}{ Sex } & \multicolumn{2}{|c|}{$\begin{array}{c}\text { Group (A) } \\
(\mathrm{n}=15)\end{array}$} & \multicolumn{2}{|c|}{$\begin{array}{l}\text { Group (B) } \\
\quad(n=16)\end{array}$} & \multirow{2}{*}{$p$-value } \\
\hline & No. & $\%$ & No. & $\%$ & \\
\hline Male & 9 & 60.0 & 4 & 25.0 & 0.073 \\
\hline Female & 6 & 40.0 & 12 & 75.0 & \\
\hline Total & 15 & 100 & 16 & 100 & \\
\hline
\end{tabular}

$p$ : $p$-value for comparing between the two studied groups.

*: Statistically significant at $p<0.05$.

Table (3): Comparison between two groups as regard to patient's site.

\begin{tabular}{|c|c|c|c|c|c|}
\hline \multirow{2}{*}{ Site } & \multicolumn{2}{|c|}{$\begin{array}{l}\text { Group (A) } \\
(n=15)\end{array}$} & \multicolumn{2}{|c|}{$\begin{array}{c}\text { Group (B) } \\
\quad(n=16)\end{array}$} & \multirow{2}{*}{$p$-value } \\
\hline & No. & $\%$ & No. & $\%$ & \\
\hline Lower & 7 & 46.7 & 5 & 31.3 & 0.678 \\
\hline Middle & 3 & 20.0 & 4 & 25.0 & \\
\hline Upper & 5 & 33.3 & 7 & 43.8 & \\
\hline Total & 15 & 100 & 16 & 100 & \\
\hline
\end{tabular}

$p$ : $p$-value for comparing between the two studied groups.

*: Statistically significant at $p<0.05$.

Table (4): Comparison between two groups as regard to patient's protrusion.

\begin{tabular}{lcccc}
\hline $\begin{array}{l}\text { Protrusion } \\
(\mathrm{mm})\end{array}$ & $\begin{array}{c}\text { Group (A) } \\
(\mathrm{n}=15)\end{array}$ & $\begin{array}{c}\text { Group (B) } \\
(\mathrm{n}=16)\end{array}$ & $\mathrm{U}$ & $p$-value \\
\hline Min.-Max. & $26-38$ & $24-37$ & 85.00 & 0.175 \\
Mean \pm S.D & $32.27 \pm 4.367$ & $30.38 \pm 4.703$ & & \\
\hline
\end{tabular}

U: Mann-Whitney test.

$p$ : $p$-value for comparing between the two studied groups.

*: Statistically significant at $p<0.05$.

Table (5): Comparison between two groups regarding patient's duration of surgery.

\begin{tabular}{lcccc}
\hline $\begin{array}{l}\text { Duration of } \\
\text { surgery }\end{array}$ & $\begin{array}{c}\text { Group (A) } \\
(\mathrm{n}=15)\end{array}$ & $\begin{array}{c}\text { Group (B) } \\
(\mathrm{n}=16)\end{array}$ & $\mathrm{U}$ & $p$-value \\
\hline Min.-Max. & $30-60$ & $30-70$ & 101.50 & 0.470 \\
& & & & \\
Mean \pm S. D & $43.67 \pm 10.431$ & $46.25 \pm 10.408$ & &
\end{tabular}

$\mathrm{U}$ : Mann-Whitney test.

$p$ : $p$-value for comparing between the two studied groups.

*: Statistically significant at $p<0.05$. 
Table (6): Comparison between two groups as regards to patient's complications.

\begin{tabular}{|c|c|c|c|c|c|}
\hline \multirow[t]{2}{*}{ Complications } & \multicolumn{2}{|c|}{$\begin{array}{l}\text { Group (A) } \\
(\mathrm{n}=15)\end{array}$} & \multicolumn{2}{|c|}{$\begin{array}{l}\text { Group (B) } \\
(\mathrm{n}=16)\end{array}$} & \multirow{2}{*}{$\begin{array}{c}p- \\
\text { value }\end{array}$} \\
\hline & No. & $\%$ & No. & $\%$ & \\
\hline \multicolumn{6}{|l|}{ Intraoperative: } \\
\hline Wound infection & 1 & 6.7 & 3 & 18.8 & 0.600 \\
\hline Skin necrosis & 2 & 13.3 & 3 & 18.8 & 1.000 \\
\hline \multicolumn{6}{|l|}{ After week: } \\
\hline Hematoma & 1 & 6.7 & 2 & 12.5 & 1.000 \\
\hline \multicolumn{6}{|l|}{ After 1 month: } \\
\hline Skin loss & 2 & 13.3 & 3 & 18.8 & 1.000 \\
\hline Suture extrusion & 2 & 13.3 & 4 & 25.0 & 0.685 \\
\hline \multicolumn{6}{|l|}{ After 6 months: } \\
\hline Suture extrusion & 3 & 20.0 & 4 & 25.0 & 1.000 \\
\hline $\begin{array}{l}\text { Conchal set back } \\
\text { distance }\end{array}$ & 1 & 6.7 & 2 & 12.5 & 1.000 \\
\hline
\end{tabular}

$p: p$-value for comparing between the two studied groups.

*: Statistically significant at $p<0.05$.

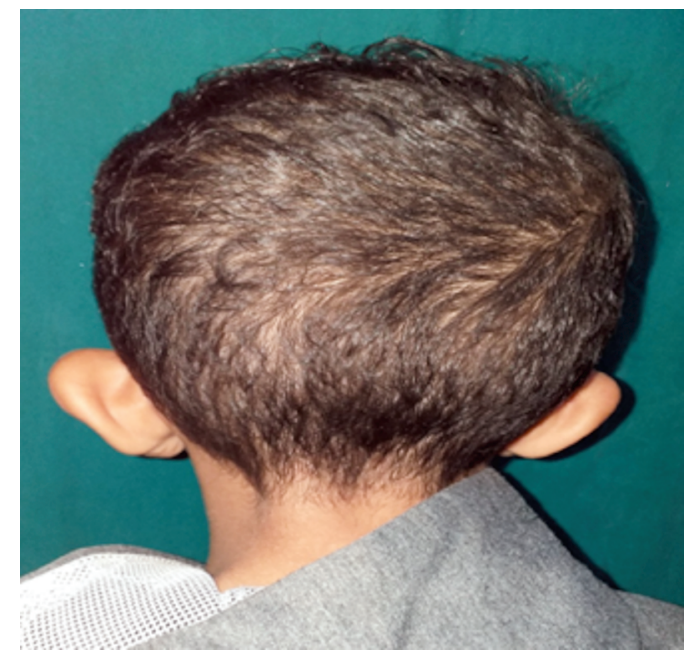

Fig. (2): Male patient 5 years old with prominent ear (uppermiddle-lower) pre-operative in group A.

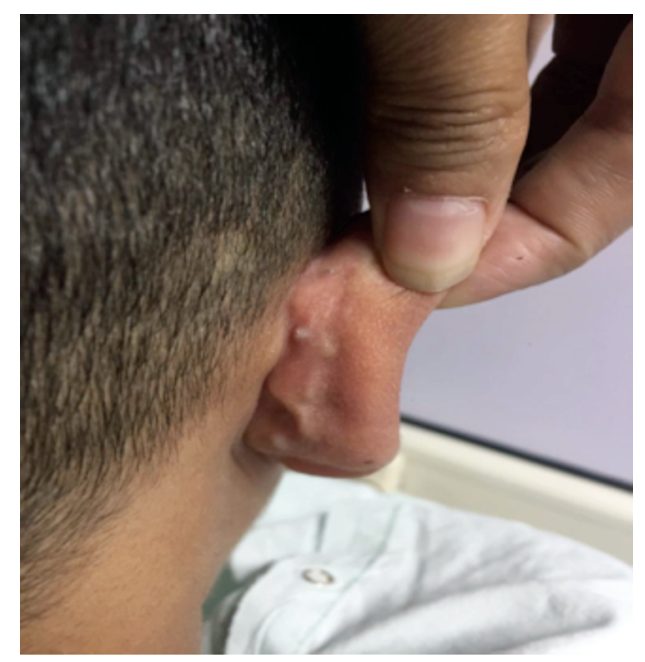

Fig. (4): Male patient 11 years old with suture extrusion after 6 months of otoplasty without postauricular fascial flap group B.

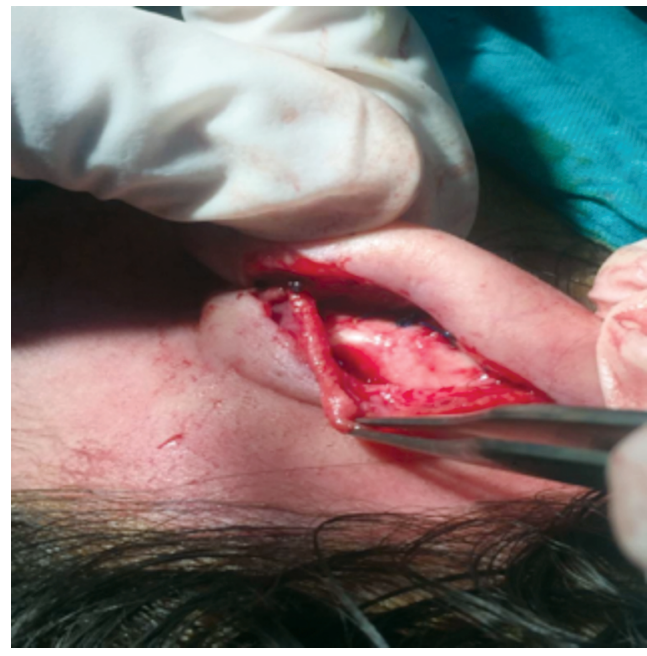

Fig. (1): Male patient 7 years old with prominent ear intraoperative in group A otoplasty during elevation postauricular fascial flap to cover Musterde suture.

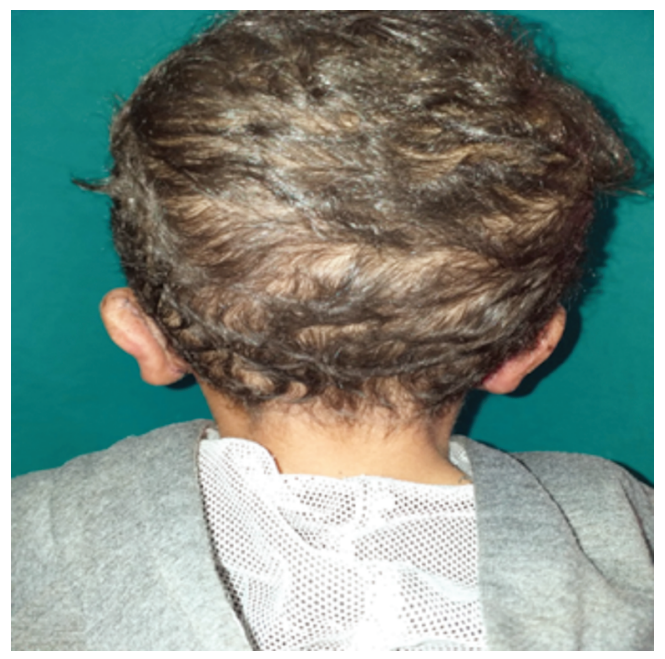

Fig. (3): Male patient 5 years old with prominent ear (uppermiddle-lower) post-operative in group A.

\section{DISCUSSION}

One of the common congenital ear deformities is prominent ear, affecting about $5 \%$ of the general population. Deficiency or prominence of the ear may cause both aesthetic and psychological problems either in children or adult patients [12].

The current study aimed to compare otoplasty with post-auricular fascial flap and otoplasty without the flap as regard deformities set back and hide if suture extrusion.

This prospective comparative study was conducted on 31 patients presented with congenital prominent ear deformity in The Plastic Surgery Department, Faculty of Medicine, Menoufia University, Patients were classified into 2 groups: Group (A): Including 15 patients with Otoplasty 
with post-auricular fascial flap. Group (B): Including 16 patients with otoplasty without post-auricular fascial flap.

Analysis of our findings revealed that age in Group (A) was ranged between 4-7 years with mean \pm S.D. $5.13 \pm 0.915$ years while in Group (B) was ranged between 4-7 years with mean \pm S.D. $5.38 \pm 1.204$ years.

Regarding sex, there were no statistically significant differences between groups. Group (A); $9(60.0 \%)$ were male and $6(40.0 \%)$ were female while in Group (B) 4(25.0\%) were male and $12(75.0 \%)$ were female. There was no statistically significant difference between groups.

Sinha and Richard, [13] aimed to evaluate the prospective outcome of post-auricular fascial flap in a research done on 227 patients and declared that the age range was 6:16 years with a ratio between male and female 5:3.

Regarding the site, the current work showed that in group (A) there were 5(33.3\%) in the upper site, $3(20.0 \%)$ in the middle site, and $7(46.7 \%)$ in the lower site. Group (B) showed that 7(43.8\%) in the upper site,4(25.0\%) in the middle site, and $5(31.3 \%)$ were in the lower site. There was no statistically significant difference between groups.

The protrusion in Group (A) was ranged between $26-38 \mathrm{~mm}$ with mean \pm S.D. $32.27 \pm 4.367 \mathrm{~mm}$ while in Group (B) was ranged between $24-37 \mathrm{~mm}$ with mean \pm S.D. $30.38 \pm 4.703 \mathrm{~mm}$. There were no statistically significant differences between groups where $p=0.175$.

In the study done by Horlock et al., [14] on fifty-one patients (26 female and 25 male) who had otoplasty operations using the mentioned technique, there was a total of 96 ears, six unilateral procedures, and 45 bilateral operations. The patient's age range was 4-72 years. Analysis of the ear protrusion was done pre-operatively in 40 patients ( 3 unilateral, 37 bilateral), and in 34 patients was performed post-operatively ( 3 unilateral, 31 bilateral). The mean of pre-operative protrusion was $29 \mathrm{~mm}$ for both ears $(20-38 \mathrm{~mm}$ for right ears and $21-37 \mathrm{~mm}$ for left ears).

As regard patient complications, the current study showed that there was no statistically significant difference between groups. In 2012, Sinha and Richard, [13] reported the largest study of patients undergoing prominent ear correction where he employed a postauricular fascial flap technique in 227 pediatric patients. The author reported the following complication rates: $4.8 \%$ recurrence, $2.64 \%$ suture extrusion, $1.32 \%$ keloid formation, and $0.44 \%$ skin necrosis.

Qader et al., [15] reported that major suturerelated complications included signs of chronic inflammation, (redness, itching, pain, and discharge) stitch granuloma, sinus formation, or extrusion. Minor complications include palpable knots or visible fine threads that are asymptomatic. Neither major nor minor suture-related complications were observed in these patients. No keloid or hypertrophic scar has been seen in these patients. Bleeding occurred in one ear $(4.7 \%)$ that was treated with pressure and wound care and stopped without the need for reoperation or hematoma formation. In reviewing other complications in this dissertation like prominent upper and lower poles in one patient and hidden helix in two patients, those complications could occur with any procedure, and they might be due to improper technique rather than to be caused by the flap.

Shokrollahi et al., [16] in another report had only $1.7 \%$ suture extrusion in one ear that is again lower than other articles. In a period of 8 months, none of our patients report neither major nor minor suture-related complications. The flap also produces a smooth outline of antihelix by applying a uniform pull of differing degrees on each of the ear poles.

In another study done by Kang and Kerstein, [17] declared that all adverse events occurred at $\leq 12$ months following insertion.

\section{Conclusion:}

The otoplasty with post-auricular fascial flap provides good patient and parent satisfaction with a natural harmonious look and limited complications particularly concerning sutures displaying its effectiveness in preventing these complications, but with no real difference between otoplasty with and without post-auricular fascial flap. Based on our findings, we recommend further studies on larger sample size and larger geographical scale to emphasize our conclusion.

\section{REFERENCES}

1- Karaca H. and Yildinm D.: Fascio-perichondrial Flap with Approximal Base Combined with Prominent Ear Surgery, Medical and Dental Journal, P. 18-90, 2017.

2- Charles H. and Nilgen T.: Otoplasty and Ear Reduction, Chapt 20; P. 523, 531, 2018.

3- Peker F. and Celikoz B.: Otoplasty: Anterior Scoring and Posterior Rolling Technique in Adult. Aesthetic plastic sur, 26: P, 267, 273, 2002. 
4- Janis J., Rohrich R. and Gutowski K.: Otoplasty. Plast. Recontr. Surg., 115 (4): 60e-72e, 2005.

5- Schaverian M.V. and Stewart K.J.: Posterior Suturing with Postsurgical Fascial Flap Otoplasty, Advanced cosmetic Otoplasty, P. 371-379, 2010.

6- El Bestar, Saker W.M., Keshk T.: The Post- Auricular Fascial Flap as a Refinement in Cartilage Sparing Otoplasty, Egypt J. Plast. Recontr. Surg., Vol. 3, P. 231-234, 2009.

7- Mandal A., Bahia H. and Ahmad T.: Comparison of Cartilage Scoring and Cartilage Sparing Otoplasty. A study of 203 cases. J. Plast. Recontr. Aesthet. Surg., 59 (11): 1170-6, 2006.

8- Schaverian M.V., Al-Busaidis and Stewart K.J.: Longterm Results of Posterior Suturing with Postauricular Fascial Flap Otoplasty. J. Plast. Recontr. Aesthet. Surg., 63 (9): 1997-51, 2010

9- Hatef D.A., Meaike J.D. and Hollier L.H.: Otoplasty: Operative Dictations in Plastic and Reconstructive Surgery, p. 257-9, 2016

10- Kotz S., Balakrishnan N., Read C.B. and Vidakovic B.: Encyclopedia of statistical sciences. $2^{\text {nd }}$ ed. Hoboken, N.J.: Wiley-Interscience, 2006.

11- Kirkpatrick L.A. and Feeney B.C.: A simple guide to IBM SPSS statistics for version 20.0. Student ed. Belmont, Calif.: Wadsworth, Cengage Learning, 2013.
12- Basat S.O., Askeroğlu U., Aksan T., et al.: New Otoplasty Approach: A Laterally Based Postauricular Dermal Flap as an Addition to Mustarde and Furnas to Prevent Suture Extrusion and Recurrence. Aesth Plast Surg., 38: 83-89. https://doi.org/10.1007/s00266-013-0269-z, 2014.

13- Sinha M. and Richard B.: Postauricular fascial flap and suture otoplasty: A prospective outcome study of 227 patients, 65 (3): 367-371. doi: 10.1016/ j.bjps.2011.09.018, 2012.

14- Horlock N., Misra A. and Gault D.T.: The postauricular fascial flap as an adjunct to Mustardé and Furnas type otoplasty. Plast. Reconstr. Surg., 108 (6): 1487-1490; discussion 1491, 2001.

15- Qader A., Dana Abdulmagid Abdilkarim and Salah Ahmed Mohammed: The Effectiveness of Posturicular Fascial Flap as an Adjunct to Suture Otoplasty, Kurdistan Journal of Applied Research (KJAR) Journal homepage: http://www.spu.edu.iq/kjar/index.php ISSN 2411-7684 (print) - 2411-7706, Fascial Flap and Suture Otoplasty, Ari et al., 2016.

16- Shokrollahi K., Cooper M.A. and Hiew L.Y.: A new strategy for otoplasty. J. Plast. Reconstr. Aesthet. Surg., 62 (6): 774-81, 2009.

17- Kang N.V. and Kerstein R.L.: Treatment of Prominent Ears with an Implantable Clip System: A Pilot Study. Aesthetic Surgery Journal, 36 (3), NP100-NP116. https://doi.org/10.1093/asj/sjv182, 2016. 